\title{
Personality attributes of children with behavior problems. An exploratory analysis with the Exner Comprehensive System of the Rorschach Inkblot Test and implications for the socio-historical clinical practice approach
}

\author{
Ana Beatriz Saraiva ${ }^{\mathrm{a}, \mathrm{b} *}$, Jorge Ferreira ${ }^{\mathrm{a}}$ \\ ${ }^{a}$ Quintino Aires Institute, Lisbon, Portugal \\ ${ }^{\mathrm{b}}$ CIEC - Research Center on Child Studies, Lisbon, Portugal \\ *Corresponding author. E-mail: abeatriz_saraiva@hotmail.com
}

From a Relational-Historical theoretical framework applied to clinical psychological practice, this study examines the data set underlying the personality attributes of different groups of children with behavior problems as demonstrated on the Rorschach Inkblot Test. To define the groups, categories were established from parents' descriptions of their own children. This procedure allowed for the formation of three major psychological profiles: hyperkinetic, oppositional defiant, and antisocial (Saraiva \& Ferreira, 2016). The major goal of this study is data exploration in a clinical setting, in order to investigate whether and in what ways groups of hyperkinetic, oppositional defiant, and antisocial children differ. These profile characteristics are important issues embraced by both psychodiagnosis and psychotherapy. The participants for this study were 39 Portuguese children, who were private clinic clients; there were 24 boys and 15 girls between the ages of 6 and 14. Their personality attributes were measured using the Rorschach Inkblot Test (Rorschach, 1994), and the Comprehensive System developed by Exner (1991, 1993, 2000) was applied, with the support of the clinical interpretation provided by Quintino-Aires $(1999 ; 2009 ; 2012 ; 2014)$. Comparison of the three profiles showed four common aspects of personality structure: a deficit in cognitive perceptual skills, lack of self-control, limited relational skills, and low self-esteem. Differences in the three profiles revealed factors related to the functional characteristics of specific behavior patterns. Children with the hyperkinetic psychological profile show factors of difficulty in controlling their activity, impulsivity, and overlapping emotions about conscious action. Those with the oppositional defiant profile revealed factors of low self-confidence, low trust in others, high pessimism, loneliness, and structural stress. Finally, those with the antisocial profile had factors of a deficit in coping skills, lack of verbalization of affects and emotions, and egotism.

Keywords: hyperkinetic, oppositional, antisocial, Exner Comprehensive System for the Rorschach Inkblot Test, postnonclassical psychology 


\section{Introduction}

Disruptive behavior disorders are among the easiest of mental health childhood disorders to identify because they are expressed through objective behaviors such as tantrums, aggression, excessive argumentativeness, stealing, and other forms of defiance or intolerance to authority. Disorders like oppositional defiant disorder (ODD) and conduct disorder (CD) first attract notice when they interfere with academic performance, or family and peer relationships. Behaviors typical of disruptive disorders can have some resemblance to attention-deficit/hyperactivity disorder (ADHD) - particularly when impulsivity and hyperactivity are also involved - but $\mathrm{ADHD}, \mathrm{ODD}$, and $\mathrm{CD}$ are considered separate conditions that can occur independently (APA, 2013; OMS, 1996).

Both the Diagnostic and Statistical Manual of Mental Disorders, 5th edition (DSM-5), and the International Statistical Classification of Diseases and Related Health Problems, 10th Edition (ICD-10) have established diagnostic criteria for ADHD, ODD, and CD. A comparison of the two diagnostic approaches finds slight discrepancies between the two. Table 1 presents the structure of classification and respective codes regarding these behavioral disorders.

North American studies have estimated the prevalence of early childhood behavioral disorders, but numbers can vary significantly from study to study, depending on the purpose, methodology for population selection, and criteria used to diagnose the disorders and identify functional impairment. The results of these studies indicate that about one out of every three to four youths is estimated to meet the lifetime criteria for a DSM mental disorder (Costello et al, 2004). After anxiety disorders, considered the most frequent condition in children, ADHD is the most common neurobehavioral childhood disorder as it affects large numbers of children throughout the world (Solovieva \& Quintanar, 2015). As previously noted, there is also no agreement on the prevalence of ADHD. Nevertheless, a Spanish study reveals a range of incidence from $1.5 \%$ to $18 \%$ in different populations (Cardo, 2010); another study estimates that approximately $5.29 \%$ meet the criteria for ADHD (Polanczyk et al., 2007). According to the DSM-5, the annual prevalence of CD is $2 \%$ to $10 \%$, with a median of $4 \%$ (APA, 2013). ODD has an estimated lifetime prevalence of 10.2\% (Dickstein, 2010).

Considering the previously cited psychopathological diagnostic classifications for which there are generally agreed-upon definitions, it is important to discuss and develop the concepts that the study addresses. DSM-5 has recently reclassified ADHD from "Disorders Usually First Diagnosed in Infancy, Childhood or Adolescence" to "Neurodevelopmental Disorders." ADHD is a behavioral condition that makes focusing on everyday requests and routines especially challenging. Children with ADHD typically have trouble organizing tasks and activities, fail to pay attention to details, are unable to remain seated in appropriate situations, and find it difficult to stay focused, make plans, and consider the consequences of their actions. Excessive talking, fidgeting, noisiness, difficulty playing quietly, and problems adapting to changing situations represent another set of symptoms. It is common to subdivide the disorder into two groups - inattention and hyperactivity/impulsivity - both having to be consistent to a degree that is maladaptive and inconsistent with the child's developmental level (APA, 2013). Children with $\mathrm{ADHD}$ can also be defiant, socially challenging or aggressive, and there is known 
Table 1. Comparison between the taxonomy of the DSM-5 and ICD-10

\begin{tabular}{ll}
\hline \multicolumn{1}{c}{ DSM-5 } & \multicolumn{1}{c}{ ICD-10 } \\
\hline Attention-Deficit/Hyperactivity Disorder & Attention-deficit hyperactivity disorders (F90) \\
$\begin{array}{l}\text { (314.01) Category: Neurodevelopmental } \\
\text { Disorders }\end{array}$ & Code F90.0 \\
& $\begin{array}{l}\text { Attention-deficit hyperactivity disorder, predo- } \\
\text { minantly inattentive type }\end{array}$ \\
Code 314.00 & Code F90.1 \\
Predominantly inattentive presentation & Attention-deficit hyperactivity disorder, pre- \\
& dominantly hyperactive type \\
Code 314.01 & Code F90.2 \\
Predominantly hyperactive/impulsive & Attention-deficit hyperactivity disorder, com- \\
presentation & bined type \\
& Code F90.8 \\
& Attention-deficit hyperactivity disorder, other \\
& type \\
& Code F90.9 \\
& Attention-deficit hyperactivity disorder, unspeci- \\
& fied type \\
\hline Conduct disorder (312.81) & Conduct disorder (F91) \\
Code 312.81 & Code F91.0 \\
Conduct disorder, childhood-onset type & Conduct disorder confined to family context \\
Code 312.82 & Code F91.1 \\
Conduct disorder, adolescent-onset type & Conduct disorder, childhood-onset type \\
Code 312.89 & Code F91.2 \\
Conduct disorder, unspecified onset & Conduct disorder, adolescent-onset type \\
& Code F91.3 \\
& Oppositional Defiant disorder \\
& Code F91.8 \\
& Other Conduct disorders \\
& Code F91.9 \\
& Conduct disorder, unspecified \\
&
\end{tabular}

Oppositional Defiant disorder (313.81)

co-morbidity and premorbidity between ADHD and ODD (Pardini \& Fite, 2010). $\mathrm{ADHD}$ has been reconsidered in the latest edition of the DSM, so that it now features three different types: the predominantly inattentive type; the predominantly hyperactive-impulsive type; and finally, the combined type, when both core symptoms coincide (APA, 2013).

The concepts of CD and ODD draw from psychopathology and characterize two kinds of antisocial behavior that are clinically significant (Kazdin \& Whitley, 2006). The inclusion of a chapter on disruptive, impulse-control, and conduct disorders is new to the DSM-5; it includes Oppositional Defiant Disorder (ODD), Conduct Disorder (CD), and Intermittent Explosive Disorder. According to DSM-5 criteria, CD is characterized by behavior that violates either the rights of others, or age-appropriate societal norms or rules. The essential feature is a repetitive and persistent pattern, and the symptoms must cause significant impairment in social, academic, or occupational functioning. The disorder is typically diagnosed prior to adulthood. CD may also be described as juvenile delinquency in criminal taxonomy, where both psychological and legal definitions are combined. It is also well 
established that CD can be a premorbid condition for Antisocial Personality Disorder (APD), as in adult criminality, especially when lack of empathy and deficient affect are fundamental traits.

The symptoms of ODD are now grouped into three types: angry/irritable mood, argumentative/defiant behavior, and vindictiveness (APA, 2013). Broader labels such as disruptive, challenging, or troublesome may encompass both $\mathrm{CD}$ and ODD, reflecting the impact that the behavior has on disturbing the social environment. Whatever the case may be, a child behavior disorder consists of a marked pattern of social impairment and maladjustment that results in repetitive actingout behavior, not just in an isolated incident.

The present study decided on an alternative terminology - behavior problem - as it offered a wider definition and subsumed a variety of behaviors. To put the subtypes of pattern behaviors into focus, a broader taxonomy was adopted, namely the hyperkinetic, oppositional defiant, and antisocial behavior profiles.

Regardless of the difficulties hyperkinetic children may display, specifically in close relationships like those with family members or schoolmates and teachers, few attempts have been made to understand the relationship between specific features of hyperkinetic behavior and socio-emotional functioning, using standardized tests like the Rorschach Inkblot Test (Cotugno, 1995). When associated with the Exner Comprehensive System, the Rorschach provides useful data on a wide range of personality attributes, and important insight into personality structure and the complex relationship between behavioral patterns and the effect of these on socioemotional functioning. It is clear that the Rorschach test should not be the only instrument used, but an important part of an overall psychological evaluation. In fact, the Rorschach test is a vital complement to more standardized and even survey instruments, and neuropsychological investigation should play a leading role in any rigorous clinical evaluation (e.g., Akhutina \& Pylaeva, 2011; Kholodnaya \& Emelin, 2015; Solovieva \& Quintanar, 2015; and others).

The aim of this study was to examine the data set underlying personality attributes as demonstrated on Exner's Rorschach Comprehensive System in children labeled with hyperkinetic, oppositional defiant and antisocial profiles. For accomplishing this main objective, similarities and differences in personality attributes of the three groups were analyzed. Results are presented and discussed in light of the cultural-historical perspective (Luria, 1973; Vygotsky, 1993) and the specific clinical interpretation of the Quintino Aires Institute (Quintino-Aires, 1999; 2009; 2014).

\section{Perspective of the Vygotsky-Luria school}

When looking into the philosophical science that dominates human science's conceptualization and methodology, particularly about psychology, one realizes that classical Western thinking, following Cartesianism, provides theories and paradigms that emphasize fragmentation and compartmentalization of knowledge about mind and body. This conception defines the direction and still underlies observations and practices of dealing with child behavioral problems. Contemporary psychology, based on philosophical science, has provided the foundation for the classification of scientific approaches, leading to an actual state of scientific knowl- 
edge characterized by the concept of postnonclassical science (e.g., Pervichko \& Zinchenko, 2014; Quintino-Aires, 2014; Zinckenko \& Pervichko, 2012; 2013).

Hyperactivity, as in $\mathrm{ADHD}$, is a relatively recent historical category in child studies. In contemporary clinical psychology supported by the Vygotsky-Luria school, syndrome analysis is one of the most essential methodological principles used for dealing with complex self-developing open systems and studying psychic phenomena like personality attributes (Luria, 1973; Vygotsky, 1993; Zinchenko \& Pervichko, 2012). The conceptualization of a particular type of syndrome is essential to structural analysis of complex phenomena, to clarify the distinction between the manifestation of psychological factors and the mechanisms responsible for their emergence and functioning. As Zeigarnik's works show, this enlightenment benefits the psychological interpretation of clinical phenomenology (Nikolaeva, 2011).

\section{Method}

\section{Sample}

Our sample comprised 39 Portuguese children, 24 males and 15 females, of ages between 6 and 14. These children were selected from a group of clinical patients at a Portuguese Health Institute which has applied the Historical-Cultural approach for many years. Children with behavior problems were classified into three groups: "hyperkinetic," 20 children (51.3\%); "oppositional defiant," 11 children (28.2\%); and "antisocial," 7 children (20.5\%).

The assignment of children to each group was done according to three criteria: a) the description by the family members who accompanied the children to the first consultation, usually the parents; b) interaction with the child in the first consultation; and c) the assessment made by senior psychologists using neuropsychological investigation with a Lurian battery (BIN, Neuropsychological Research Battery; Juvêncio, 2015; Rua, 2015) and a personality assessment with Rorschach Inkblot Test. This psychodiagnostic methodology is traditional for historical and cultural psychology, and it is an alternative to the psychometrical and cognitive approach.

Table 2. Descriptive data for age in the three groups

\begin{tabular}{lccc}
\hline & Range & $\chi$ & SD \\
\hline Hyperkinetic (H) & $6-12$ & 8.94 & 1.92 \\
Oppositional Defiant (OD) & $6-12$ & 9.91 & 1.81 \\
Antisocial (AS) & $6-14$ & 9.88 & 2.80 \\
\hline
\end{tabular}

The Rorschach Test was administered and scored by examiners formally trained in the use of Exner's Comprehensive System (1991, 1993, 2000). Clinical case notes provided a picture of the client's reports on the child's behavior at home and school, the client's reasons for entering therapy, the child's current symptomatology, and his/her clinical diagnosis. The data collected was analyzed by four judges with training and practice in clinical psychology, who discussed the meaning of the children's behavior reported by parents, and the results of their assessment. 
Three clinical groups were organized according to the criteria proposed by the classification systems of psychological disorders (ICD-10 and DSM-V). Hyperkinetic $(\mathrm{H})$ signified "hyperactivity, agitation, restlessness, low concentration, lack of attention." Oppositional Defiant (OD) signified "oppositional, defiant, rudeness, disobedience, resistance." And antisocial (AS) signified "lying, running away from school/home, abuse, aggressiveness, unruliness." In Tables 2 and 3 we report the age and gender distributions for the children from the three groups.

Table 3. Frequency of gender in the three groups

\begin{tabular}{cccc}
\hline & H & OD & AS \\
\hline Male & 13 & 4 & 7 \\
Female & 7 & 7 & 1 \\
\hline
\end{tabular}

Because of the exploratory nature of this study and considering the size of the sample, test differences in age and gender were not analyzed. Nevertheless, age averages were considered similar, and some differences in gender distribution of the three clinical groups were registered, particularly in the antisocial sample, which consisted of only one female.

\section{Instruments}

The goal of identifying personality attributes of several groups with behavior problems was pursued using the Exner Comprehensive System of the Rorschach Inkblot Test $(1991,1993,2000)$. The Rorschach Inkblot Test is a projective technique composed by 10 psychodiagnostic plates with abstract stimuli made of inkblots. Upon observing each plate, individuals have to express what the ink spots resemble. The Exner Comprehensive System allows a broad picture of the psychological dynamics of the individual. This system evaluates the personality structure to three groups of key variables: Group I - the Perceptual-Thinking Index (PTI), the Depression/ Apathy Index (DEPI), and the Coping Deficit Index (CDI); Group II - control and tolerance of stress; and Group III - dominant styles (or trends) of personality, namely, affective features, self-perception, and interpersonal perception. The three groups of different indices are used for the calculation of three groups defined by qualities of mental functioning: The «cognitive triad» refers to information processing, ideation, and cognitive mediation.

All results obtained in this study are presented and discussed in light of the clinical interpretation provided by Quintino-Aires (1999; 2009; 2012; 2014). This author provided maladaptation and clinical-reference values, and a clinical-oriented interpretation for the variables, chapters, and constellations of the Exner Comprehensive System, in order to obtain an individualized understanding of the patients.

\section{Procedure}

In order to provide a uniform coding procedure among the psychologists, data was collected through standard evaluation procedures by clinical psychologists of a health institution certified in Rorschach administration and Exner Comprehensive 
System procedures. Data was analyzed with SPSS.20. Coding of the Rorschach protocols had an agreement coefficient of 0.95 among four independent judges with training in clinical psychology.

\section{Results}

In general, the Rorschach constellations did not indicate psychopathology for either group, but the Depression/Apathy Index (DEPI) was considered clinically significant in all three profiles. Table 4 illustrates the first findings on major constellations. In line with Exner's (1993) recommendations, singular variables were not reviewed, but were considered in groups of variables or clusters, relating each other to specific characteristics of personality. We further analyzed similarities and differences in the results between the groups.

Table 4. Means of major constellations

\begin{tabular}{cccc}
\hline & H & OD & AS \\
\hline PTI & 2.85 & 2.00 & 2.13 \\
DEPI & 3.85 & 3.55 & 3.63 \\
CDI & 3.05 & 3.55 & 3.38 \\
SCON & 5.20 & 4.91 & 5.38 \\
\hline
\end{tabular}

Table 5. Frequency of major constellations with abnormal values (\%)

\begin{tabular}{cccc}
\hline & $\mathrm{H}$ & OD & AS \\
\hline PTI & 30.0 & 18.2 & 25.0 \\
DEPI $=3$ & 35.0 & 36.4 & 37.5 \\
DEPI $>3$ & 60.0 & 54.6 & 50.0 \\
CDI & 15.0 & 27.3 & 0.0 \\
SCON & 5.0 & 0.0 & 12.5 \\
\hline
\end{tabular}

Neither the Hypervigilance Index (HVI) nor the Obsessive Style Index (OBS) were present, and, hence, were not considered in the previous tables. The most significant indicator was that all three groups had a DEPI mean greater than 3 ; this is explained by the fact that $50 \%$ or more of each group had a DEPI higher then 3 (4 or higher).

The comparison of profiles shows common aspects in four dimensions: cognitive/perceptual skills, self-regulation, relational skills, and self-esteem. As to the first dimension, cognitive/perceptual skills, in all three groups a marked deficit in the reception, interpretation, and meaning of stimuli arising from experiencing the environment was found (W). This deficit directly influences the style of approaching the world, expectations, and resources (W:M) and, in a broader sense, processing. Cognitive mediation was also impaired, namely self-awareness and awareness of others $(\mathrm{X}+, \mathrm{F}+)$; there was a difficulty in starting relationships with others (X-), 
and a tendency for defensiveness (Xu). When ideation was considered, a lack of cognitive flexibility (a:p) was found. Table 6 presents values of indicators for these dimensions.

Table 6. Frequency of Rorschach indicators with abnormal values (\%)

\begin{tabular}{|c|c|c|c|c|}
\hline & & $\mathbf{H}$ & OD & AS \\
\hline \multirow[t]{6}{*}{ Processing } & Tendency W & 90.0 & 36.4 & 75.0 \\
\hline & Tendency Dd & 0.0 & 27.3 & 25.0 \\
\hline & Both tendency W and Dd & 0.0 & 27.3 & 0.0 \\
\hline & $\mathrm{W}<\mathrm{M}+50$ & 40.0 & 54.5 & 37.5 \\
\hline & $\mathrm{W}>\mathrm{M}+100$ & 45.0 & 36.4 & 62.5 \\
\hline & DQv & 50.0 & 72.7 & 37.5 \\
\hline \multirow[t]{6}{*}{ Mediation } & $\mathrm{P}$ & 75.0 & 72.0 & 50.0 \\
\hline & $\mathrm{X}+$ & 100.0 & 100.0 & 100.0 \\
\hline & $\mathrm{F}+$ & 95.0 & 100.0 & 100.0 \\
\hline & $\mathrm{X}-$ & 90.0 & 81.8 & 87.5 \\
\hline & S- & 50.0 & 27.3 & 25.0 \\
\hline & $\mathrm{Xu}$ & 100.0 & 90.9 & 87.5 \\
\hline \multirow[t]{3}{*}{ Ideation } & $\mathrm{a}<\mathrm{p}+2$ & 45.0 & 27.3 & 37.5 \\
\hline & $a>p+2$ & 45.0 & 63.6 & 50.0 \\
\hline & M- & 30.0 & 33.4 & 12.5 \\
\hline \multirow[t]{3}{*}{ Affect } & $\mathrm{F}: \mathrm{C}$ & 70.0 & 72.7 & 62.5 \\
\hline & PureC & 30.0 & 18.2 & 37.5 \\
\hline & Comb:R & 75.0 & 90.9 & 87.5 \\
\hline \multirow[t]{4}{*}{ Self-perception } & $3 r+(2) / \mathrm{R}$ & 75.0 & 90.9 & 75.0 \\
\hline & $\mathrm{Fr}+\mathrm{rF}$ & 5.0 & 9.1 & 12.5 \\
\hline & $\mathrm{FD}$ & 90.0 & 72.7 & 87.5 \\
\hline & MOR & 35.0 & 45.5 & 12.5 \\
\hline \multirow[t]{5}{*}{ Interpersonal } & $\mathrm{COP}$ & 85.0 & 90.9 & 87.5 \\
\hline & $\mathrm{AG}$ & 85.0 & 90.9 & 100.0 \\
\hline & $\mathrm{H}:(\mathrm{H})+\mathrm{Hd}+(\mathrm{Hd})$ & 95.0 & 100.0 & 87.5 \\
\hline & $(\mathrm{H})+(\mathrm{Hd}):(\mathrm{A})+(\mathrm{Ad})$ & 20.0 & 36.4 & 75.0 \\
\hline & $(\mathrm{Bt}+2 \mathrm{Cl}+\mathrm{Ge}+\mathrm{Ls}+2 \mathrm{Na}) / \mathrm{R}$ & 40.0 & 72.7 & 50.0 \\
\hline \multirow[t]{6}{*}{ Control } & EA & 35.0 & 54.5 & 25.0 \\
\hline & es & 75.0 & 72.7 & 100.0 \\
\hline & Adj es & 75.0 & 63.6 & 100.0 \\
\hline & $\mathrm{FM}<3$ & 65.0 & 45.5 & 62.5 \\
\hline & $\mathrm{FM}>4$ & 20.0 & 18.2 & 12.5 \\
\hline & $C^{\prime}$ & 70.0 & 27.3 & 75.0 \\
\hline
\end{tabular}


The second dimension evinced a deficit in self-control, poor elaboration (FM), precipitate judgement of others $(\mathrm{H}:(\mathrm{H})+\mathrm{Hd}+(\mathrm{Hd}))$, and lack of self-analysis $(\mathrm{FD})$. The third dimension concerned relational skills, where low levels of empathy (Comb:R) were observed, an impairment in cognitive mediation, difficulties in bonding (COP), low assertiveness (AG), and a failure to have an accurate representation of others due to hasty judgment $(\mathrm{H}:(\mathrm{H})+\mathrm{Hd}+(\mathrm{Hd}))$. The fourth dimension that all three groups had in common was related to self-esteem $(3 r+(2) / R)$. All participants showed low self-esteem and social identity, and this was associated with a lack of resources and expectations (W:M), sadness, and general lack of energy (DEPI).

But different aspects were also found when comparing all three profiles in relation to the functional characteristics of each behavior pattern. Within the Hyperkinetic $(\mathrm{H})$ group, the children had difficulty regulating action $(\mathrm{F}: \mathrm{C})$, were more impulsive, and their emotions overrode conscious reflexive action (PureC).

Children with an Oppositional Defiant profile (OD) had a higher lack of trust in themselves and others $(3 r+(2) / R)$; in this case, low expectations $(W: M)$ and resources (EA), higher pessimism (MOR), loneliness ( $(\mathrm{Bt}+2 \mathrm{Cl}+\mathrm{Ge}+\mathrm{Ls}+2 \mathrm{Na}) / \mathrm{R})$, and intrinsic stress were the important distinguishing variables (Adj es). Another core aspect of this profile is that relationships with others and the environment are more difficult (COP, AG; $(\mathrm{H}:(\mathrm{H})+\mathrm{Hd}+(\mathrm{Hd}))$, and more tense. There is a restriction in these children's ability to focus, as they have low involvement, less conventionality (P), less flexibility (a:p), and low awareness of themselves and others (S-). Disturbance of thought also plays a key role (M-), with higher susceptibility to the environment due to a lack of self-organization (DQv).

Children in the Antisocial (AS) group had a greater deficit of resources for positive relationships, and a lack of resources to deal with stress (EA), like coping skills; in this sense they registered intrinsic stress (Adj es). This group also revealed a deficit in organizing internal information, difficulty in verbally expressing emotions and feelings $\left(C^{\prime}\right)$, cognitive rigidity (a:p), a tendency to use a great deal of fantasy in representation of others $((\mathrm{H})+(\mathrm{Hd}):(\mathrm{A})+(\mathrm{Ad}))$, and to a global approach to the world (W). Another set of characteristics of this group related to the bias in self-representation, because greater egotism was present, less disposition for selfanalysis (FD), and lower expectations about their own resources (EA).

\section{Discussion}

The findings in this study allow a glimpse into hypothetical scenarios of the dynamic structure of personality profiles, namely the relation to one's self, others, and the world within a specific, unique, and singular Eigenwelt. The predominance of problems of self-control, precipitate judgment, and overlapping conscious emotions characteristic of the Hyperkinetic profile involved more motor and affective features needing rehabilitation of the ability to control and plan action with important psychomotor characteristics. Neuropsychological rehabilitation, or even working with play therapy with a focus on shared attention, will introduce the regulation of alternating communication through joint action (Leal, 2010).

The Oppositional Defiant profile showed less self-confidence, less trust in others, higher pessimism and loneliness, low resources and expectations, and rather 
tense relationships. This showed a need for self-awareness through knowing the other. Rehabilitation should be centered in more dialogue, and the experienced "other" should function as a vehicle for consensual meaning, by putting together, naming, and referencing the process.

The Antisocial profile registered a lack of resources to deal with stress, difficulty in expressing emotions and feelings, and egotism. The interpretation of this profile provides us with a need for feeling the other, knowing that the other exists, and finding the limits in one's self. Confrontation, a work routine, and clear boundary setting are needed in therapy.

In clinical practice, hyperactivity can often be a behavior pattern intersecting all three profiles. Aggression is also a behavior that can often be manifest in all of the profiles. Differential diagnosis is essential when dealing with these syndromes, and specific considerations regarding treatment need to be made if serious work is to be pursued (Solovieva \& Quintanar, 2015). Finally, an important aspect of the Oppositional Defiant and Antisocial profiles concerns the underlying intentionality behind the behavior. Both can be seen as defiant patterns of behavior, but while Oppositional Defiant types manifest reactive and non-intentional aggression, Antisocial types present instrumental and intentional aggression.

\section{Conclusion and future directions}

With these findings, one can further develop Leal's (1988) proposed psychopathological system based on the Genetic Affectology theory that presents seven stages of socio-emotional development. To some extent this rationale also has points of similarity with Elkonin's leading activity concept (Quintino-Aires, 2014).

Quintino-Aires (2014) argues:

"Steps of Genetic Affectology", by Maria Rita Mendes Leal, serve as the "grammar," morphology and syntax of personality that allow us to listen/read with sense the phonemes produced by the patient, which are then the symptoms expressed in actions and speech. (p. 42)

This exploratory study with groups of children with behavior problems is an example of how syndrome analysis can be used. But further research with larger samples and quasi-experimental designs could help diagnosis and provide guidelines for making clinical psychological prognoses and suggesting therapeutic plans for each particular client. Further research could also have a focus on testing parental and school environment variables in longitudinal studies and revisit the way ADHD is approached, considering the historical and cultural influence on meanings when diagnosing and treating difficult children.

\section{Acknowledgements}

The authors would like to acknowledge the staff of the Quintino-Aires Institute, particularly the support and help of two clinical psychologists, Susana Pereira and Patrícia Medeiros, in choosing the study group. 


\section{References}

Akhutina T. V., \& Pylaeva N. M. (2011). L. Vygotsky, A. Luria and Developmental Neuropsychology. Psychology in Russia: State of the Art, 4, 155-175.

American Psychiatric Association. (2013). Diagnostic and statistical manual of mental disorders (5th ed.). Arlington, VA: American Psychiatric Publishing.

Cardo, E., Nevot, A., Redondo, M., Melero, A., Azua, B., Banda, G. G., \& Servera, M. (2010). Trastorno por déficit de atención/hiperactividad:? un patrón evolutivo? [Attention deficit disorder/hyperactivity: an evolutionary pattern?]. Revista de Neurología, 50 (3), 143-147.

Costello, E. J., Mustillo, S., Keller, G., \& Angold, A. (2004). Prevalence of psychiatric disorders in childhood and adolescence. In: B. L. Levin, J. Petrila, K. D. Hennessy, (Eds.). Mental Health Services: a Public Health Perspective, Second Edition. (pp. 111-128). Oxford, UK: Oxford University Press.

Cotugno, A. J. (1995). Personality attributes of attention deficit hyperactivity disorder (ADHD) using the Rorschach inkblot Test. Journal of Clinical Psychology, 51(4), 554-561.

Dickstein, D. P. (2010). Oppositional Defiant Disorder. Journal of the American Academy of Child \& Adolescent Psychiatry, 49 (5): 435-436.

Exner, J. E. (1991). The Rorschach: A Comprehensive System. Vol. 2: Interpretation (2nd ed.). New York: Wiley.

Exner, J. E. (1993). The Rorschach: A Comprehensive System. Vol. 1: Basic foundations (3rd ed.). New York: Wiley.

Exner, J. E. (2000). A primer for Rorschach interpretation. Asheville, NC: Rorschach Workshops. Juvêncio, J. (2015). Contributo ao Desenvolvimento de um Instrumento de Investigação Neuropsicológica: Um estudo de validação da Bateria de Investigação Neuropsicológica (BIN) em crianças portuguesas de 5 anos de idade [Contribution to the Development of a Neuropsychological Research Instrument: A validation study of the Neuropsychological Research Battery (BIN) in 5-year-old Portuguese children]. (Unpublished doctoral thesis). Universidade Fernando Pessoa, Porto, Portugal.

Kazdin, A. E., \& Whitley, M. K. (2006). Comorbidity, case complexity, and effects of evidencebased treatment for children referred for disruptive behaviour. Journal of Consulting and Clinical Psychology, 74, 455-67.

Kholodnaya, M. \& Emelin, A. (2015). Resource function of conceptual and metacognitive abilities in adolescents with different forms of dysontogenesis. Psychology in Russia: State of the Art, 8 (4), 101-113.

Leal, R. (1988). O fenómeno humano da relação dialógica [The human phenomenon of dialogic relationship]. Cadernos de Consulta Psicológica, 4, 91-96.

Leal, M. R. M. (2010). Step by Step Constructing the Self. Lisboa: Fim de Século.

Luria, A. R. (1973). The Working Brain. An Introduction to Neuropsychology. London: Penguin Books.

Nikolaeva, V. V. (2011). B. W. Zeigarnik and Pathopsychology. Psychology in Russia: State of the Art, 4, 176-192.

Organização Mundial da Saúde (1996). Classificação Estatística Internacional de Doenças e Problemas Relacionados à Saúde: CID-10 [International Statistical Classification of Diseases and Related Health Problems: ICD-10], Décima revisão. Trad de Centro Colaborador da OMS para a Classificação de Doenças em Português. Vol 2, 3 ed. São Paulo: EDUSP.

Pardini, D. A., \& Fite, P. J. (2010). Symptoms of conduct disorder, oppositional defiant disorder, attention-deficit/hyperactivity disorder, and callous-unemotional traits as unique predictors of psychosocial maladjustment in boys: Advancing an evidence base for DSM-V. Journal of the American Academy of Child and Adolescent Psychiatry, 49 (11), 1134-1144. 
Pervichko, E. \& Zinchenko, Y. (2014). Postnonclassical Methodology in Clinical Psychology: Opportunities and Perspectives of the Vygotsky-Luria School. Open Journal of Social Sciences, 2, 90-95.

Polanczyk G., de Lima M. S., Horta B. L., Biederman J., Rohde L. A. (2007). The worldwide prevalence of ADHD: a systematic review and metaregression analysis. American Journal of Psychiatry, 164, 942-948.

Quintino-Aires, J. (1999). Notas do curso de pós-graduação em psicologia clínica e neuropsicologia [Notes on the postgraduate course in clinical psychology and psychotherapy]. Lisboa: Instituto de Psicologia Aplicada e Formação.

Quintino-Aires, J. (2006). A socio-historical approach in psychotherapy with adults. Psychology for Latin America, 5. Retrieved from http:// www.psicolatina.org/Cinco/adultos.html

Quintino-Aires, J. (2009). Manual de Interpretação Rorschach-Exner Vol.II [Rorschach-Exner's clinical interpretation]. Lisboa: Instituto de Psicologia Aplicada e Formação.

Quintino-Aires, J. (2012). Post-classical psychology in forensics in crime: A perspective. In F. Almeida \& M. Paulino (Eds.), Profiling, Vitimologia \& Ciências Forenses: Perspetivas atuais [Profiling, victimology and forensics: current perspectives] (pp. 17-47). Lisboa: Pactor.

Quintino-Aires, J. (2014). Contribution to postnonclassical psychopathology. Psychology in Russia: State of the Art, 7(3), 35-49.

Rorschach, H. (1994). Psychodiagnostics Plates. Bern: Verlag Hans Huber AG.

Rua, A. (2015). Contributo ao Desenvolvimento de um Instrumento de Investigação Neuropsicológica: Um estudo de Validação da BIN em crianças portuguesas de 7 anos [Contribution to the Development of a Neuropsychological Research Instrument: A validation study of the Neuropsychological Research Battery (BIN) in 7-year-old Portuguese children] (Unpublished doctoral thesis). Universidade Fernando Pessoa, Porto, Portugal.

Saraiva, A. B. \& Ferreira, J. (2016, June). Rorschach indicators in Child Behavioral Problems 6-14. Data exploration in clinical setting. Paper presented at the Estoril Vigotsky Conference, Estoril, Portugal.

Solovieva, Yu. \& Quintanar, L. (2015). Qualitative syndrome analysis by neuropsychological assessment in preschoolers with attention deficit disorder with hyperactivity. Psychology in Russia: State of the Art, 8(3), 112-124.

Vygotsky, L.S. (1993). The diagnostics of development and the pedological clinic for difficult children. In Rieber,R. W., \& Carton, A. S. (Eds.) The Collected Works of L. S. Vygotsky: The Fundamentals of Defectology (Abnormal Psychology and Learning Disabilities), New York, Plenum Press, 2, 241-291.

Zinchenko, Y. P. \& Pervichko, E. I. (2013). Nonclassical and postnonclassical epistemology in Lev Vygotsky's cultural-historical approach to clinical psychology. Psychology in Russia: State of the art, 1, 43-56.

Zinchenko Y. P., Pervichko E. I. (2012). The methodology of syndrome analysis within the paradigm of «qualitative research in clinical psychology». Psychology in Russia: State of the Art, $5,157-184$. 